in La Seu d'Urgell, Spain, the second was organised in 1998 in Fregene, Italy and the third in 1999, during the week of the eclipse in Briey, France, on the line of total darkness. We had a cloudy eclipse, but fortunately we could observe it. The fourth one was held in July 2000 in Tavira, Portugal. About 50 participants are involved in each Summer School. In the last, participants came from 14 countries. The activities are organised in General Lectures, Working Groups and Workshops for reduced groups and day and night Observations. To increase communication, each Summer School has three official languages: the language of the host country, English and another well-known by the participants. The proceedings are published beforehand with all the contents to facilitate participation. Each paper appears in English and another language.

\title{
The Leonids Observation Project by High-School Students all over the World
}

\section{B. Suzuki et al., National Astronomical Observatory, Japan}

We organized the Leonids observing network that comprised of 276 observation teams consisting of about 3,000 senior high-school students in Japan on Nov. 17 1998. We counted the visible meteors with our naked eyes. It was a simple method, but the many data enabled us to discuss the structure of the dust trail. However, the base-line is so short that we could not discuss the structure in full detail. In 1999, we organized a worldwide network of senior high-school students. The network is comprised of 307 teams from 23 countries. The base-line of our new project is the size of the Earth. We succeeded in making 20 hours continuous observations with this network. One of the observational teams in Tanzania encountered the Leonid meteor storm. We report on the scientific results and the educational aspects of these projects. (Web site: http://www.leonids.net/) (Leonids '98-'99 staff - co-authors - are A. Miyashita, M. Okyudo, H. Agata, T. Mizuno, T. Hamane K. Watanabe of Japan, C. Pennypaker, A. Gould, K. McCarron, G. Reagan and K. Meredith, of the U.S.A.)

\section{New Student Laboratory Work about Pulsational Phenomena in Astronomy}

Salakhutdin N. Nuritdinov, National University of Uzbekistan, Tashkent, Uzbekistan

The pulsation phenomenon is inherent to most types of object and it plays a great role at certain stages in the evolution of objects in the universe. That is why students must study this phenomenon in the framework of laboratory hours. Often the study of these phenomena is reduced to an analysis of some differential equations with variable coefficients. A class of these equations is connected with the stability problem of the oscillations of self-gravitating systems (S.Nuritdinov, Sov. Astron., 1985, 29, 293) . In order to carry out this laboratory work every student is required to compose a computer program using the periodical solution stability method and the parameter resonance theory. The program will find 